\title{
A T-shape diphosphinoborane palladium(0) complex
}

\author{
Patrick Steinhoff and Michael E. Tauchert ${ }^{*}$
}

\author{
Letter \\ Address: \\ Institute of Inorganic Chemistry, RWTH Aachen University, \\ Landoltweg 1, D-52074 Aachen, Germany \\ Email: \\ Michael E. Tauchert ${ }^{\star}$ - Michael.Tauchert@ac.rwth-aachen.de \\ * Corresponding author \\ Keywords: \\ ambiphilic ligand; coordination chemistry; diphosphinoborane; \\ organometallics; palladium
}

Beilstein J. Org. Chem. 2016, 12, 1573-1576.

doi:10.3762/bjoc. 12.152

Received: 18 April 2016

Accepted: 04 July 2016

Published: 22 July 2016

This article is part of the Thematic Series "Organometallic chemistry".

Guest Editor: B. F. Straub

(C) 2016 Steinhoff and Tauchert; licensee Beilstein-Institut. License and terms: see end of document.

\begin{abstract}
The reaction of $\mathrm{CpPd}\left(\eta^{3}-\mathrm{C}_{3} \mathrm{H}_{5}\right)$ with the new diphosphinoborane ligand derivative $\left(o-\mathrm{PCy}_{2}-\mathrm{C}_{6} \mathrm{H}_{4}\right)_{2} \mathrm{BPh}{ }^{\mathbf{C y}} \mathbf{D P B} \mathbf{B}^{\mathbf{P h}}$ affords the T-shape complex $\left({ }^{\mathbf{C y}_{\mathbf{D P B}}}{ }^{\mathbf{P h}}\right) \operatorname{Pd}(0) \mathbf{9}$, which was characterized by X-ray analysis.
\end{abstract}

\section{Introduction}

The amplification of traditional bidentate chelating $\mathrm{L}_{2}$-type ligands with a tethered borane functionality (e.g., Bourissou's diphospinoborane $\left(o-\mathrm{PR}_{2}-\mathrm{C}_{6} \mathrm{H}_{4}\right)_{2} \mathrm{BR}$ ' ligand $\left.{ }^{\mathbf{R}} \mathbf{D P B} \mathbf{R}^{\mathbf{R}}\right)$ has received considerable attention [1-3], with first catalytic applications emerging [4]. The acyclic boron group in these ligands can adopt a variety of coordination modes (Figure 1) [5].

The borane can act as a $\sigma$-acceptor ligand in case of $\eta^{1}$-B coordination (e.g., 1 [6] and 2 [7]), or as a boron containing $\pi$-ligand adopting $\eta^{2}-B, C(3)[8]$ or $\eta^{3}-B, C, C$ coordination (4 and 5) $[5,9,10]$. Changes of the hapticity appear to have significant influence onto the reactivity of the coordinated transition metal towards substrates [8]. For zerovalent palladium complexes only few examples featuring a $\eta^{1}$-type $\mathrm{Pd} \rightarrow \mathrm{B}$ interaction have been reported [6,7]. However, these complexes require phos- phines or pyridines as a stabilizing co-ligand, which can act as an inhibitor in catalytic transformations [7]. Similarly, monometallic $14 \mathrm{VE}$ palladium complexes featuring a chelating diphosphine, such as in Hofmanns Rucaphos complexes 6, are very scarce [11]. While the dative $\mathrm{Pd} \rightarrow \mathrm{B}$ bond is strong in zerovalent $\mathrm{Pd}(0)$ DPB complexes such as $\mathbf{2}$, only weak $\mathrm{Pd} \rightarrow \mathrm{B}$ interactions have been observed for the respective $\mathrm{Pd}(\mathrm{II})$ complexes $[7,12]$. Discrimination by the borane functionality between the oxidations states $\operatorname{Pd}(0) / \mathrm{Pd}(\mathrm{II})$ is of potential interest for organometallic transformations involved in homogeneous catalysis, such as the reductive elimination. Here we report the synthesis of the diphosphinoborane $\left(o-\mathrm{PCy}_{2}-\mathrm{C}_{6} \mathrm{H}_{4}\right)_{2} \mathrm{BPh}$ ligand ${ }^{C_{1}} \mathbf{D P B}^{\mathbf{P h}}$. $^{\mathbf{C y}_{\mathbf{D P B}}}{ }^{\mathbf{P h}}$ reacts with $\mathrm{CpPd}\left(\eta^{3}-\mathrm{C}_{3} \mathrm{H}_{5}\right)$ yielding monometallic zerovalent palladium complex 9 featuring a distinct $\eta^{1}$-B coordination mode, without the need of a stabilizing co-ligand. 


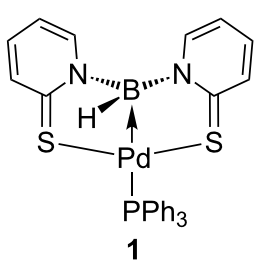<smiles>CC(C)(C)P(c1ccccc1)(c1ccccc1P(c1ccccc1)c1ccccc1)(C1CCCC1)P(c1ccccc1)c1ccccc1</smiles>

4

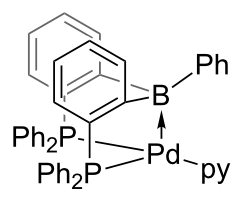

2

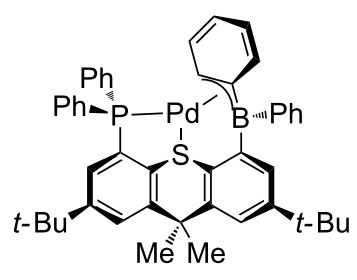

5

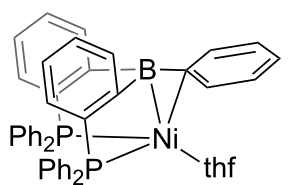

3

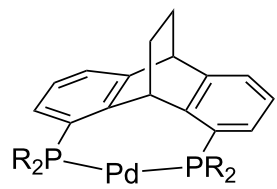

$6 \mathrm{R}=\mathrm{iPr}, \mathrm{Cy}$

Figure 1: Selected $M \rightarrow B$ coordination modes 1-5 [6-10] and Hofmann's Rucaphos complex 6 [11].

\section{Findings}

For the synthesis of ${ }^{\mathbf{C y}_{\mathbf{D P B}}}{ }^{\mathbf{P h}}$ we adapted the known reaction sequence for the production of Bourissou's $\left(o-\mathrm{PPh}_{2}-\mathrm{C}_{6} \mathrm{H}_{4}\right)_{2} \mathrm{BPh}$ ligand ${ }^{\mathbf{P h}_{\mathbf{D P B}}}{ }^{\mathbf{P h}}$ (Scheme 1) [13,14].

Starting material (2-bromophenyl)dicyclohexylphosphine (7) was produced by palladium catalyzed coupling of dicyclohexylphosphine with 1-iodo-2-bromobenzene [15]. Phosphine 7 was lithiated in diethyl ether with $n$-BuLi [16,17], affording the diethyl ether adduct $\mathbf{8}$. Reaction of $\mathbf{8}$ with 0.5 equiv of $\mathrm{PhBCl}_{2}$ in toluene at $-78{ }^{\circ} \mathrm{C}$ produced the desired ligand ${ }^{\mathbf{C}} \mathbf{D B P}{ }^{\mathbf{P h}}$ in $86 \%$ isolated yield. Typical resonances for a DPB ligand were observed in the ${ }^{31} \mathrm{P}$ NMR spectrum at $\delta 1.70$ and in the ${ }^{11} \mathrm{~B}$ NMR spectrum at $\delta 41\left(\mathrm{w}_{1 / 2}=1300 \pm 120 \mathrm{~Hz}\right)$, which are indicative for a dynamic $\mathrm{P} \rightarrow \mathrm{B}$ bond in solution [18].

${ }^{\mathbf{C y}_{\mathbf{D P}}} \mathbf{B}^{\mathbf{P h}}$ was reacted with 1 equiv of $\mathrm{CpPd}\left(\eta^{3}-\mathrm{C}_{3} \mathrm{H}_{5}\right)$ in benzene. Complete conversion towards complex 9 with equimolar formation of 5-allylcyclopenta-1,3-diene was reached within $18 \mathrm{~h}$ at $50{ }^{\circ} \mathrm{C}$. Complex 9 showed a singlet resonance at $\delta 41.0$ in the ${ }^{31} \mathrm{P}$ NMR spectrum and a broad resonance at $\delta 22$ $\left(\mathrm{w}_{1 / 2}=800 \pm 50 \mathrm{~Hz}\right)$ in the ${ }^{11} \mathrm{~B}$ NMR spectrum. High field shift and narrowing of the ${ }^{11} \mathrm{~B}$ NMR with respect to the free
${ }^{\text {Cy }}{ }_{\text {DPB }}{ }^{\mathbf{P h}}$ ligand indicated the presence of a strong dative $\operatorname{Pd}(0) \rightarrow B$ bond [7]. Despite the absence of a stabilizing co-ligand, we found complex 9 to be very stable in solution. The coordinating properties of ${ }^{\mathbf{C y}_{\mathbf{D P B}}}{ }^{\mathbf{P h}}$ deviate from those observed for its aryl derivatives $\left({ }^{\mathbf{P h}} \mathbf{D P B}{ }^{\mathbf{P h}}\left(\left(o-\mathrm{PPh}_{2}-\mathrm{C}_{6} \mathrm{H}_{4}\right)_{2} \mathrm{BPh}\right)\right.$ and $\left.{ }^{\mathbf{P h}} \mathbf{D P B}{ }^{\text {Mes }}\left(\left(o-\mathrm{PPh}_{2}-\mathrm{C}_{6} \mathrm{H}_{4}\right)_{2} \mathrm{~B}(\mathrm{Mes})\right)\right)$. For these ligands the reaction with one equivalent of $\mathrm{CpPd}\left(\eta^{3}-\mathrm{C}_{3} \mathrm{H}_{5}\right)$ leads to $50 \%$ consumption of $\mathrm{CpPd}\left(\eta^{3}-\mathrm{C}_{3} \mathrm{H}_{5}\right)$ with simultaneous formation of 5-allylcyclopenta-1,3-diene, but complete conversion of the ligand pointing towards the formation of a bisligand complex (DPB $)_{2} \mathrm{Pd}$ [7]. Unlike complex 2 we were unable to form a pyridine adduct complex by treatment of 9 with 10 equiv of pyridine. Single crystals of complex 9 suitable for X-ray diffraction analysis were grown from hexane (Figure 2).

The solid-state structure of 9 displayed a slightly distorted T-shape geometry around the palladium center. A short Pd1-B1 distance of 2.243(2) A (cf. complex 2: 2.194(3) $\AA$ ) and a significant pyramidalization at the boron center $\left(\Sigma \mathrm{B}_{\alpha}=341^{\circ}\right)$ is observed, indicating a strong $\mathrm{Pd}(0) \rightarrow \mathrm{B}$ bond. The distance between $\mathrm{C} 20$ and Pd1 was found to be 3.0805(22) $\AA$. The $\eta^{1}-\mathrm{B}$ coordination mode was well reproduced by DFT calculations (Supporting Information File 1). DFT calculations predict<smiles>O=Pc1ccccc1Br</smiles>

7
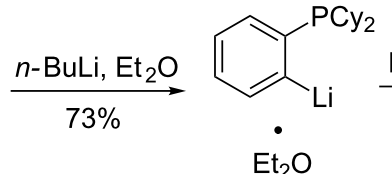

8 $\underset{86 \%}{\stackrel{\mathrm{PhBCl}_{2} \text {, toluene }}{\longrightarrow}}$
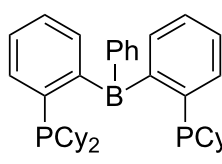

${ }^{\text {CyDPB }}{ }^{\mathrm{Ph}}$

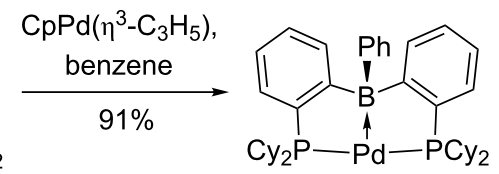

9 


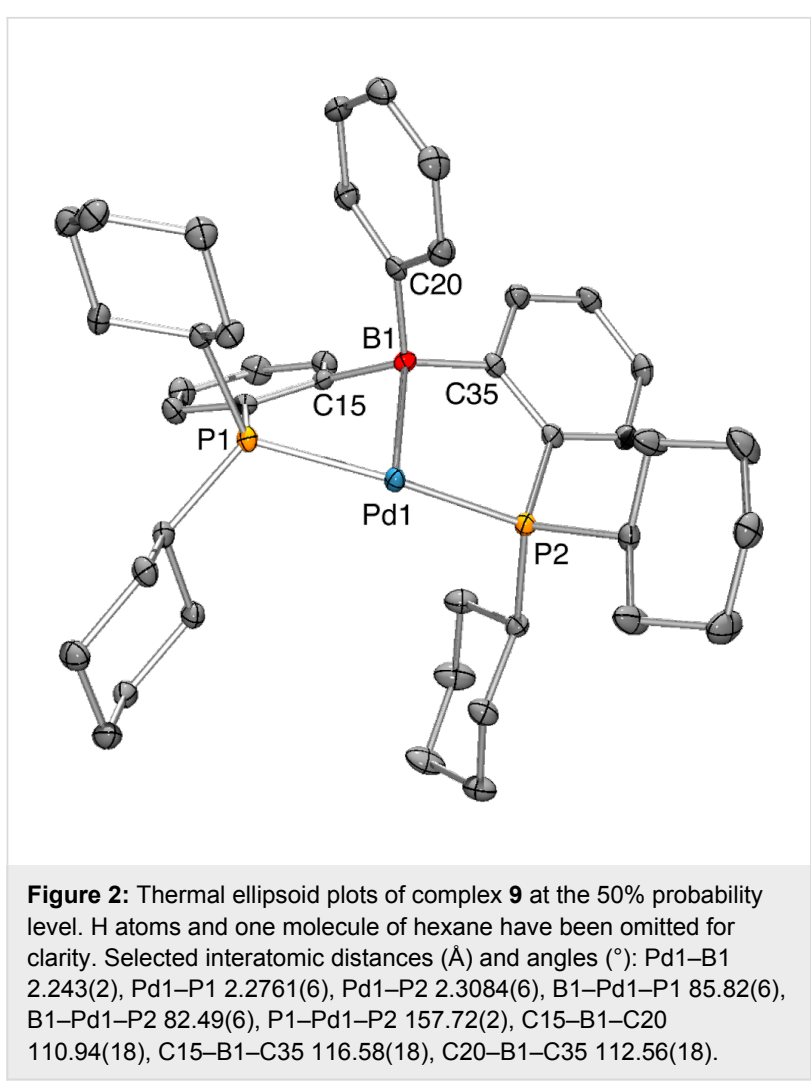

T-shape complexes with an almost linear $\mathrm{P}-\mathrm{Pd}-\mathrm{P}$ angle for model complexes $\left(\mathrm{PMe}_{3}\right)_{2} \mathrm{Pd} \rightarrow \mathrm{EX}_{3}(\mathrm{E}=\mathrm{B} ; \mathrm{X}=\mathrm{H}, \mathrm{F}, \mathrm{Cl}, \mathrm{Br}$, I) [17]. In complex 9 the trans-coordinated palladium center featured an obtuse P1-Pd1-P2 angle of 157.72(2) .

\section{Conclusion}

In conclusion we synthesized the zerovalent palladium complex $\left[\left\{\left(o-P C y_{2}-\mathrm{C}_{6} \mathrm{H}_{4}\right)_{2} \mathrm{BPh}\right\} \mathrm{Pd}(0)\right]$ 9. Complex 9 supplements the few known examples (e.g., 6 [11]) of $14 \mathrm{VE}$ palladium complexes bearing a chelating diphosphine ligand by introduction of a borane acceptor functionality.

\section{Supporting Information}

\section{Supporting Information File 1}

Experimental procedures and characterization data; crystallographic information for $9 ;{ }^{1} \mathrm{H},{ }^{11} \mathrm{~B},{ }^{13} \mathrm{C}$ and ${ }^{31} \mathrm{P}$ NMR spectra.

[http://www.beilstein-journals.org/bjoc/content/ supplementary/1860-5397-12-152-S1.pdf]

\section{Supporting Information File 2}

CIF file of 9, CCDC 1471929.

[http://www.beilstein-journals.org/bjoc/content/ supplementary/1860-5397-12-152-S2.cif]

\section{Acknowledgements}

We are grateful for financial support of this research by the Funds of the Chemical Industry (fellowships to PS and MET). We thank Q. Guo for collection of X-ray diffraction data and J. Wiesenthal for experimental assistance. We thank Prof. Dr. J. Okuda for his continuous and generous support.

\section{References}

1. Fontaine, F.-G.; Boudreau, J.; Thibault, M.-H. Eur. J. Inorg. Chem. 2008, 5439-5454. doi:10.1002/ejic.200800784

2. Amgoune, A.; Bourissou, D. Chem. Commun. 2011, 47, 859-871. doi:10.1039/C0CC04109B

3. Kameo, H.; Nakazawa, H. Chem. - Asian J. 2013, 8, 1720-1734. doi:10.1002/asia.201300184

4. Bouhadir, G.; Bourissou, D. Chem. Soc. Rev. 2016, 45, 1065-1079. doi:10.1039/C5CS00697J

5. Emslie, D. J. H.; Cowie, B. E.; Kolpin, K. B. Dalton Trans. 2012, 41, 1101-1117. doi:10.1039/C1DT11271F

6. Zech, A.; Haddow, M. F.; Othman, H.; Owen, G. R. Organometallics 2012, 31, 6753-6760. doi:10.1021/om300482m

7. Schindler, T.; Lux, M.; Peters, M.; Scharf, L. T.; Osseili, H.; Maron, L.; Tauchert, M. E. Organometallics 2015, 34, 1978-1984. doi:10.1021/acs.organomet.5b00217

8. Harman, W. H.; Peters, J. C. J. Am. Chem. Soc. 2012, 134, 5080-5082. doi:10.1021/ja211419t

9. Emslie, D. J. H.; Harrington, L. E.; Jenkins, H. A.; Robertson, C. M.; Britten, J. F. Organometallics 2008, 27, 5317-5325. doi:10.1021/om800670e

10. Cowie, B. E.; Emslie, D. J. H. Organometallics 2015, 34, 4093-4101. doi:10.1021/acs.organomet.5b00539

11. Schnetz, T.; Röder, M.; Rominger, F.; Hofmann, P. Dalton Trans. 2008, 2238-2240. doi:10.1039/b802684j

12. Bontemps, S.; Sircoglou, M.; Bouhadir, G.; Puschmann, H.; Howard, J. A. K.; Dyer, P. W.; Miqueu, K.; Bourissou, D. Chem. - Eur. J. 2008, 14, 731-740. doi:10.1002/chem.200701027

13. Sircoglou, M.; Bontemps, S.; Mercy, M.; Saffon, N.; Takahashi, M.; Bouhadir, G.; Maron, L.; Bourissou, D. Angew. Chem., Int. Ed. 2007, 46, 8583-8586. doi:10.1002/anie.200703518

14. Conifer, C. M.; Law, D. J.; Sunley, G. J.; White, A. J. P.; Britovsek, G. J. P. Organometallics 2011, 30, 4060-4066. doi:10.1021/om200341t

15. Murata, M.; Buchwald, S. L. Tetrahedron 2004, 60, 7397-7403. doi:10.1016/j.tet.2004.05.044

16. Harder, S.; Brandsma, L.; Kanters, J. A.; Duisenberg, A.; van Lenthe, J. H. J. Organomet. Chem. 1991, 420, 143-154. doi:10.1016/0022-328X(91)80257-K

17. Goedecke, C.; Hillebrecht, P.; Uhlemann, T.; Haunschild, R.; Frenking, G. Can. J. Chem. 2009, 87, 1470-1479. doi:10.1139/V09-099

18. Bontemps, S.; Bouhadir, G.; Dyer, P. W.; Miqueu, K.; Bourissou, D. Inorg. Chem. 2007, 46, 5149-5151. doi:10.1021/ic7006556 


\section{License and Terms}

This is an Open Access article under the terms of the Creative Commons Attribution License

(http://creativecommons.org/licenses/by/2.0), which permits unrestricted use, distribution, and reproduction in any medium, provided the original work is properly cited.

The license is subject to the Beilstein Journal of Organic Chemistry terms and conditions:

(http://www.beilstein-journals.org/bjoc)

The definitive version of this article is the electronic one which can be found at:

doi:10.3762/bjoc. 12.152 